\title{
Um estudo de caso sobre reflexologia e a visão
}

\author{
A case study on reflexology and vision \\ J. G. Sequeira*; D. F. Adamatti \\ Centro de Ciências Computacionais, Universidade Federal do Rio Grande (C3/FURG), 96203-900, Rio Grande-RS, \\ Brasil \\ *julianagsequeira@gmail.com
}

Este artigo tem como objetivo analisar a relação entre os lobos cerebrais com estímulos em regiões da mão com base nos conceitos de reflexologia, visto que a comprovação deste método natural não possui comprovação pela comunidade científica. Reflexologia é um método de tratamento que utiliza a massagem em áreas dos pés e das mãos como forma de tratamento. Com o intuito de averiguar esta relação planeja-se a realização de testes em diferentes regiões de diferentes pessoas na mão esquerda, inicialmente, analisa-se uma região específica. $\mathrm{O}$ primeiro teste feito foi realizado com foco na área referente à visão, visto que o lobo occipital se refere a este sentido e a mão possui uma região destinada aos olhos, parte inferior do dedo médio. A coleta de sinais cerebrais neste primeiro teste foi realizada com equipamento de eletroencefalograma (EEC) durante o estímulo na região em estudo. Para embasar os resultados obtidos, utiliza-se dos conceitos da neurociência, área que estuda o sistema nervoso com foco no cérebro de forma interdisciplinar, e reflexologia. Os resultados iniciais mostram a comprovação da relação entre as regiões, estimulada e de análise.

Palavras-chave: Reflexologia. Sinais cerebrais. Neurociência.

This paper analyzes the relationship between brain lobes with stimuli in hand regions based on the concepts of reflexology, since the proof of this natural method has no proof by the scientific community. Reflexology is a treatment method that uses massage in the areas of the feet and hands as a form of treatment. In order to ascertain this relationship, it is planned to perform tests in different regions of different people in the left hand, initially, a specific region is analyzed. The first test was performed focusing on the area related to vision, since the occipital lobe refers to this direction and the hand has a region intended for the eyes, the lower part of the middle finger. The collection of brain signals in this first test was performed with electroencephalogram equipment (EEC) during the stimulation in the region under study. In order to base the results obtained, the concepts of neuroscience are used, an area that studies the nervous system with a focus on the brain in an interdisciplinary way, and reflexology. The initial results show the confirmation of the relationship between the regions, stimulated and analyzed.

Keywords: Reflexology, Brain Signals, Neuroscience.

\section{INTRODUÇÃO}

Nos últimos anos, muitos avanços tecnológicos em áreas distintas ocorreram inclusive relacionados ao cérebro humano. $\mathrm{O}$ estudo do encéfalo é antigo, entretanto, a neurociência estuda o sistema nervoso e aborda o funcionamento do cérebro interdisciplinarmente a partir de 1970 [2].

O cérebro, principalmente, é o administrador do comportamento humano sem que haja regiões desativadas, sempre o utilizando por completo. Cada região possui a sua função e, ao ser mais requisitada, torna-se mais ativa [7].

O corpo humano possui zonas com pontos reflexos, são elas os pés e as mãos, sendo possível diagnosticar as partes em desequilíbrio. São comumente utilizados os pés para realização deste procedimento, entretanto para este trabalho utilizaram-se as mãos [6]. A reflexologia é um método natural de tratamento com base na medicina chinesa, entretanto, a comprovação científica com base na neurociência ainda não foi realizada.

Este trabalho tem por objetivo estudar as relações entre as regiões cerebrais e reflexologia, com o intuito de verificar e comprovar esta relação para a comunidade científica. Analisar-se-á o comportamento do cérebro ao estimular, inicialmente, a região da mão esquerda, referente a visão. Os resultados já obtidos mostram a validação do método baseado em massagem para tratamento. 
Com a comprovação de que ao estimular as áreas reflexas do corpo pode-se utilizar desses estímulos para criação de próteses, possibilitando movimentação para portadores de necessidades especiais.

\section{DESENVOLVIMENTO TEÓRICO}

O desenvolvimento deste trabalho é baseado nos conceitos de neurociência e reflexologia. Nesta seção são apresentados os estudos realizados sobre estes conceitos.

Neurociência é responsável pelo estudo do sistema nervoso por completo, com enfoque no cérebro [2]. O encéfalo humano é dividido em dois hemisférios, direito e esquerdo, onde cada um possui características distintas, na Tabela 1 pode-se observar as funções deles. Através dela notase que os hemisférios se complementam, ou seja, funções diferentes na mesma tarefa [7]. $\mathrm{O}$ hemisfério direito possui mais precisão nos movimentos da mão e pé esquerdo no sentido de habilidade motora, em contrapartida, o hemisfério esquerdo possui mais precisão na mão e perna direita [7].

Tabela 1: Funções dos hemisférios adaptada de Lent (2002)[7].

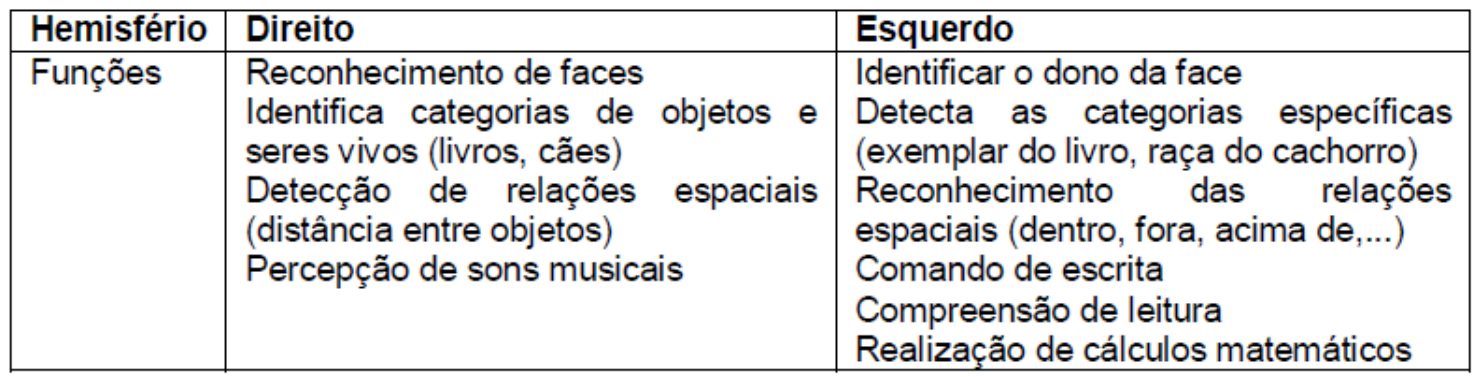

Os hemisférios são compostos por um tálamo, um hipocampo, uma amígdala, gânglios basais, um córtex central e quatro lobos. Cada lobo é responsável por um conjunto de funções [5], como se pode visualizar na Figura 1.

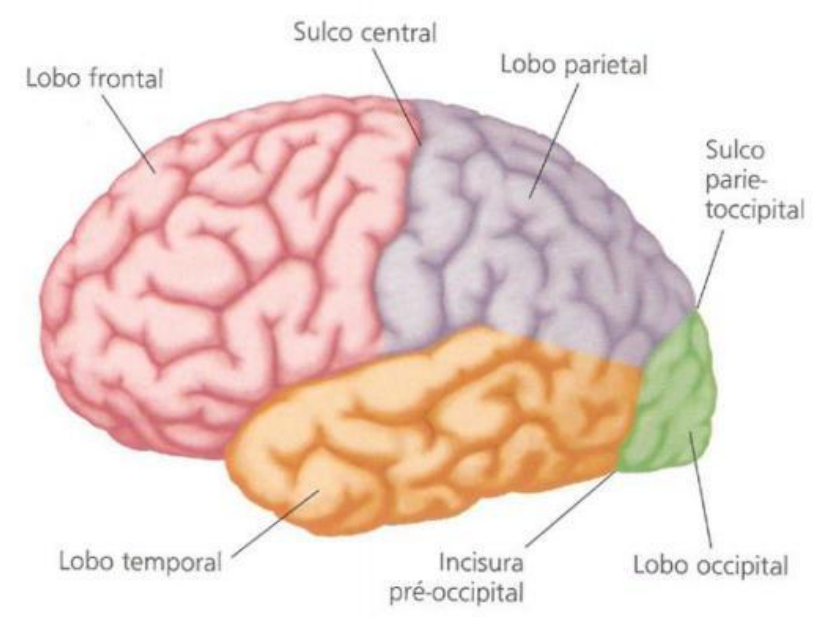

Figura 1: Os lobos dos hemisférios cerebrais: parietal, occipital, temporal e frontal [5].

Os lobos são divididos de acordo com suas funções, o lobo occipital está relacionado à visão. Já o lobo temporal à audição, compreensão linguística e alguns aspectos da visão e da memória. O lobo parietal é responsável pela sensibilidade corporal e reconhecimento espacial. O lobo frontal possui funções motoras, planejamento mental do comportamento e memória [7]. A Tabela 2, formulada por de Carvalho (2007) [4], apresenta a relação entre as regiões cerebrais, os eletrodos e suas funções. 
Tabela 2: Áreas cerebrais, eletrodos e as funções correspondentes, segundo de Carvalho (2007) [4].

\begin{tabular}{|c|c|c|}
\hline Região & Eletrodos & Funções proprietárias \\
\hline Lobo Frontal & $\begin{array}{l}\text { Fp1,Fp2,AFz,F7,F3,Fz,F4,F8, } \\
\text { FC5,FC1,FCz,FC2,FC6 }\end{array}$ & $\begin{array}{l}\text { Funções executivas (gerenciamento dos } \\
\text { recursos cognitivos/emocionais diante de } \\
\text { uma dada tarefa }\end{array}$ \\
\hline Lobo Temporal & T7,TP9,T8,T10 & Percepção de movimentos biológicos \\
\hline Lobo Pariental & P7,P3,Pz,P4,P8,P9,P10 & $\begin{array}{l}\text { Percepção somatossensorial, } \\
\text { representações especiais e percepções } \\
\text { táteis }\end{array}$ \\
\hline Lobo Occipital & $\mathrm{O} 1, \mathrm{Oz}, \mathrm{O} 2$ & $\begin{array}{c}\text { Visualização de imagens (inclusive } \\
\text { durante um diálogo) }\end{array}$ \\
\hline
\end{tabular}

A reflexologia é um método de tratamento que utiliza a massagem em áreas reflexas localizadas nas mãos e nos pés. Através da massagem destes pontos é possível realizar tratamento de partes do corpo, visto que cada área corresponde a uma parte [6]. Na Figura 2 pode-se observar as áreas referentes a cada órgão do corpo humano.

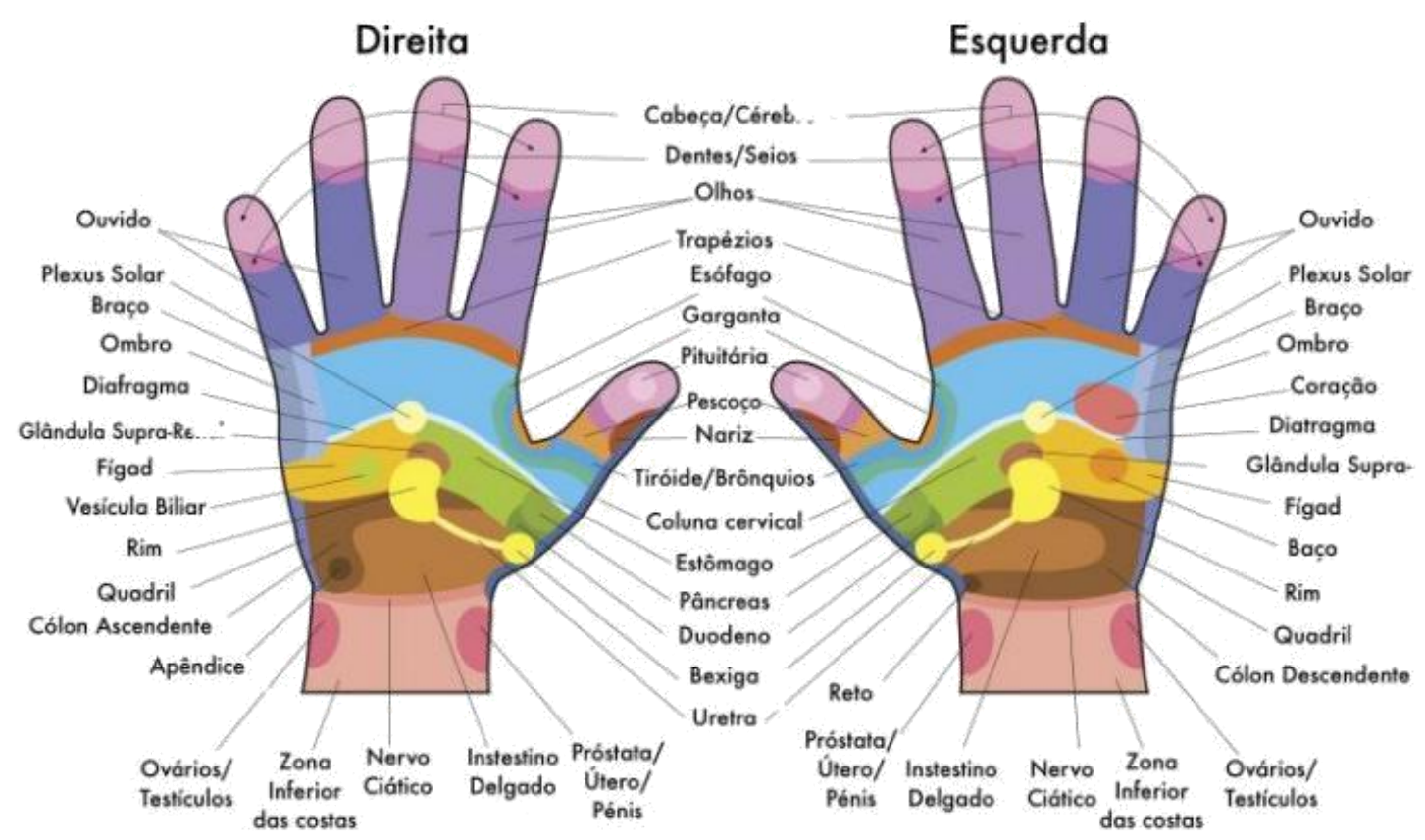

Figura 2: Orgãos referentes às regiões das mãos, segundo Hall (2013) [6].

\section{METODOLOGIA}

A metodologia para desenvolver este trabalho se dividiu em quatro etapas, como mostra a Figura 3. Inicialmente, fez-se necessário desenvolver a garra para realizar o estímulo na região da mão. Em seguida, necessitou-se aprender sobre o equipamento e software utilizados para realizar a coleta de sinais cerebrais, o equipamento de eletroencefalograma. Após estas etapas, realizou-se a coleta e por fim, analisaram-se os resultados obtidos. As três primeiras etapas serão descritas nas subseções a seguir e a análise na próxima seção. 


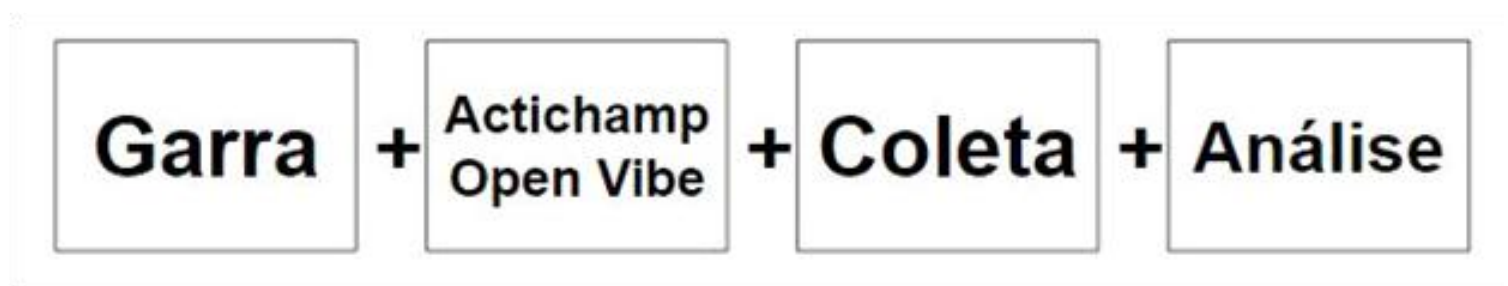

Figura 3: Etapas da metodologia proposta. Fonte: os autores.

\subsection{Garra}

Desenvolveu-se a programação de uma garra (Figura 4) com o intuito de realizar os estímulos, na região referente à visão. A frequência e o tempo de estímulo serão os mesmos (com tempos exatos), usando este equipamento, em todos os testes. A garra é composta por três servo-motores, responsáveis por realizar a movimentação da mesma. Controlou-se a movimentação do equipamento através de um microcontrolador Arduíno por cinco minutos. Pesquisou-se o tempo ideal para obtenção de resultados e, segundo Jin Shin Jyutsu® Brasil [1], a partir de 3 minutos já é possível obter resposta aos estímulos realizados, este tempo é destinado a uma técnica similar a reflexologia.
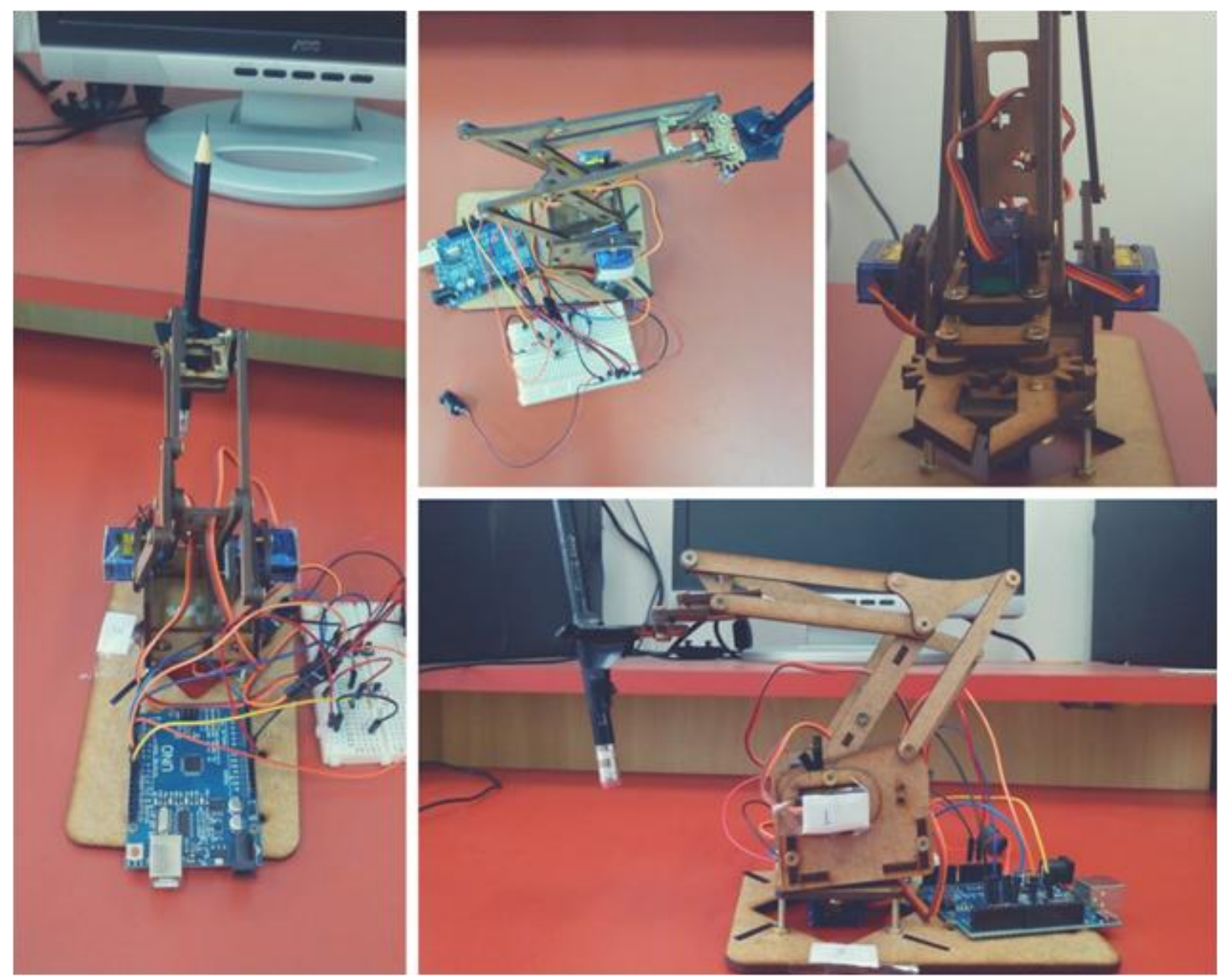

Figura 4: Garra desenvolvida para realizar os estímulos na região referente à visão. Fonte: os autores.

A montagem elétrica da garra pode-se visualizar no circuito da Figura 5. Utilizou-se uma fonte para alimentar os motores, dois botões (liga e desliga), um microcontrolador (Arduino) e um LED para sinalizar quando a garra é ligada. O código desenvolvido para a movimentação da garra encontra-se representado pelo fluxograma da Figura 6. 


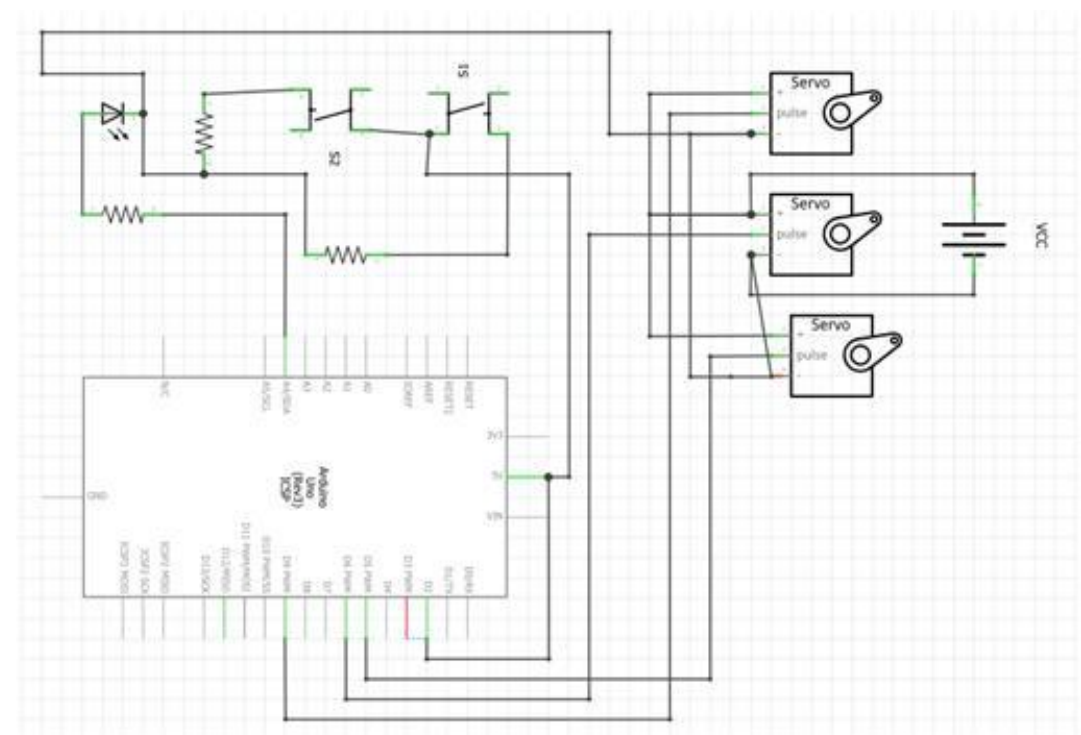

Figura 5: Circuito da garra. Fonte: os autores.

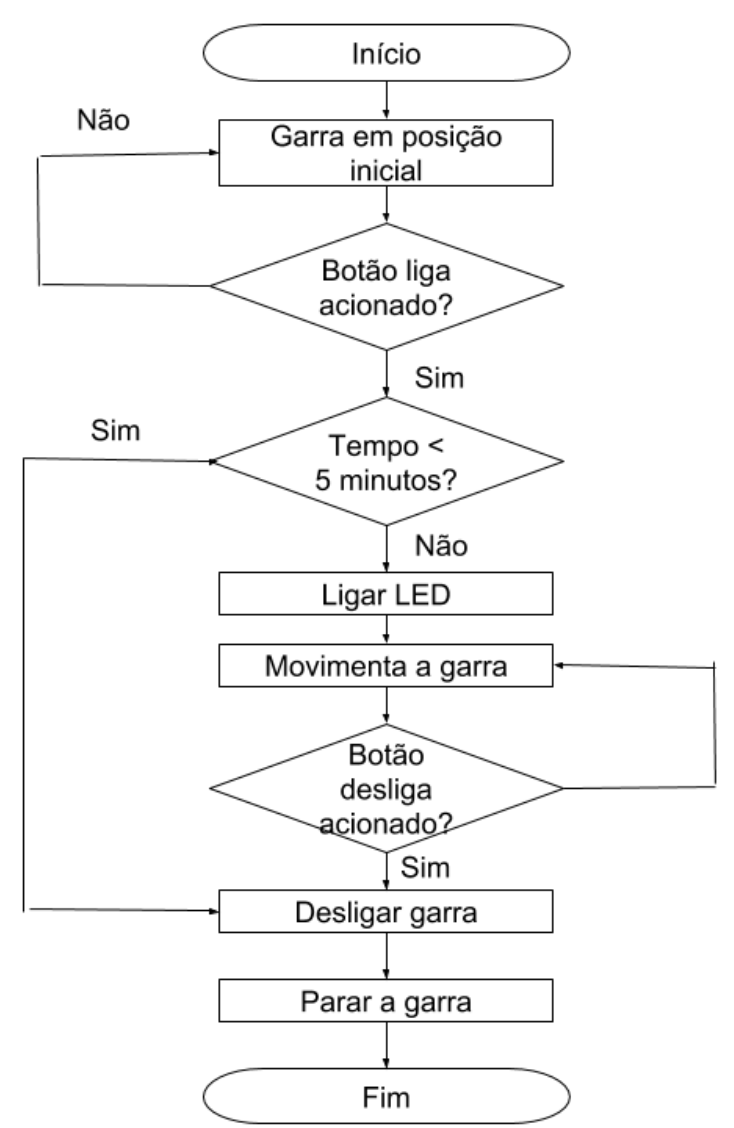

Figura 6: Fluxograma referente à programação da garra. Fonte: os autores.

\subsection{ActiChamp/Open Vibe}

Com o intuito de analisar os sinais cerebrais utilizaram-se o ActiChamp e ActiCap composto por trinta e dois eletrodos (Figura 7). Estudam-se os resultados obtidos através de teste utilizando o equipamento quando submetido ao estímulo para analisar a relação citada anteriormente. 


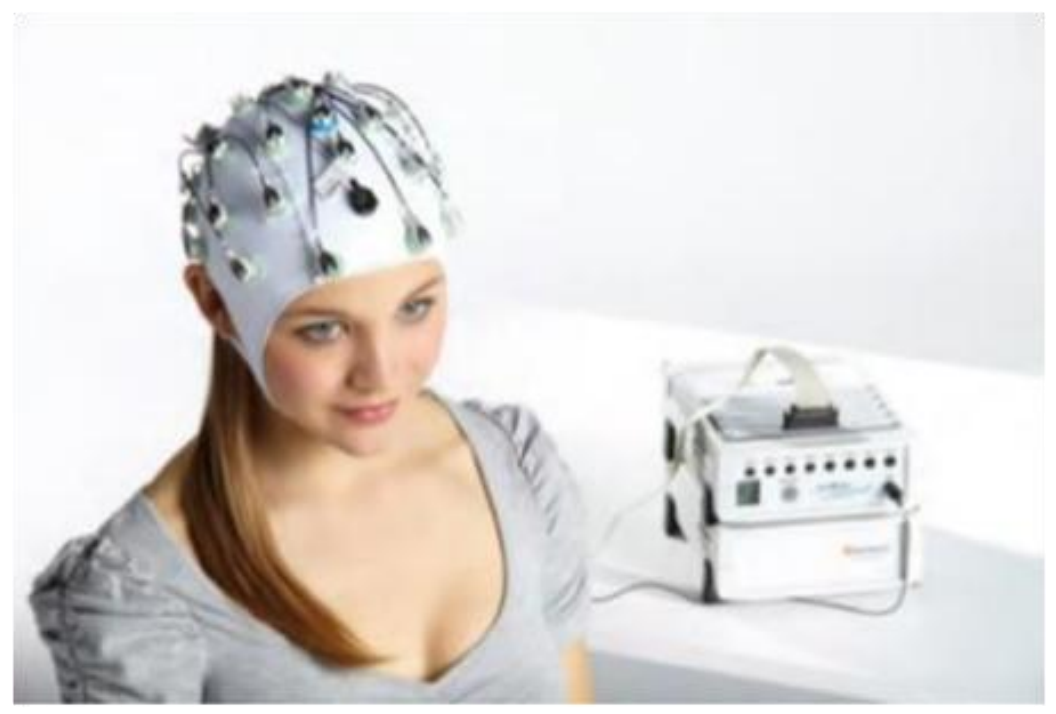

Figura 7: ActiChamp e Acticap 32 eletrodos.

Para analisar os sinais cerebrais obtidos através do ActiCap utiliza-se o software OpenVibe. Este é um programa utilizado para pesquisas na área de BCI (Brain Computer Interface) desenvolvido pela Mensia Tecnologies. Deve-se criar um cenário para receber os sinais e tornálos visíveis. Utilizaram-se dois autômatos para a realização deste trabalho para gravação dos sinais (Figura 8) e para visualizar em 2D e 3D (Figura 9) [3].

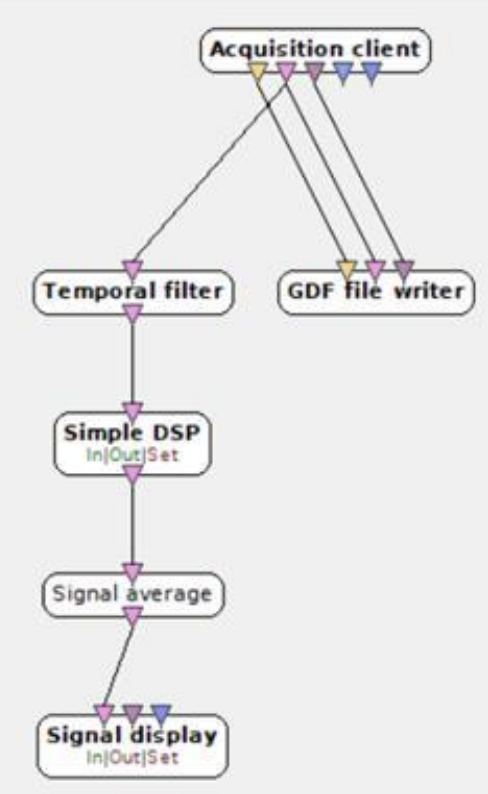

Figura 8: Autômato para gravação dos sinais cerebrais. Fonte: os autores. 


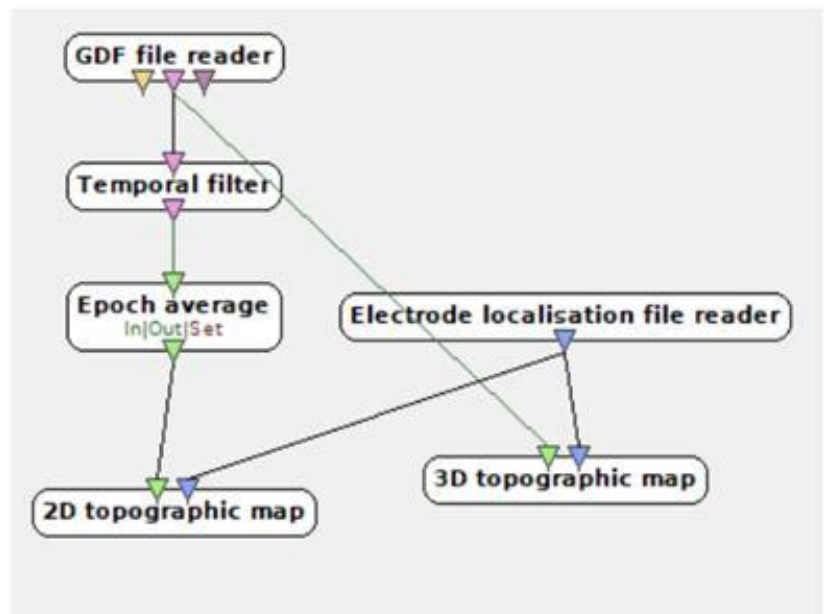

Figura 9: Autômato para visualização em 2D e 3D. Fonte: os autores.

Cada um dos blocos sem funções específicas:

- Acquisition client: Rede genérica baseada na aquisição do cliente;

- Temportal filter: Filtra os sinais que entram;

- Simple DSP: Aplica fórmulas matemáticas às matrizes;

- Signal average: Computa as médias de cada entrada;

- Signal display: Permite a visualização das ondas do EEG;

- GDF file writer: Salva os sinais coletados no formato GDF;

- GDF file reader: Lê o arquivo com formato GDF;

- Epoch average: Calcula a média das matrizes;

- 2D topographic map: Visualização em 2D;

- 3D topographic map: Visualização em 3D.

- Electrode localisation file reader: Envia as coordenadas cartesianas dos 32 canais.

\subsection{Coleta}

Visto que a visão possui uma região específica no cérebro e na mão optou-se por iniciar as coletas estimulando tal região. O local para a coleta dos sinais cerebrais necessitava-se ser silencioso, para não ativar a região do cérebro responsável pelos ouvidos/audição, e a pessoa submetida ao teste devia estar com os olhos vendados, visto que o a região de estudo é referente à visão, conforme se pode observar na Figura 10. 


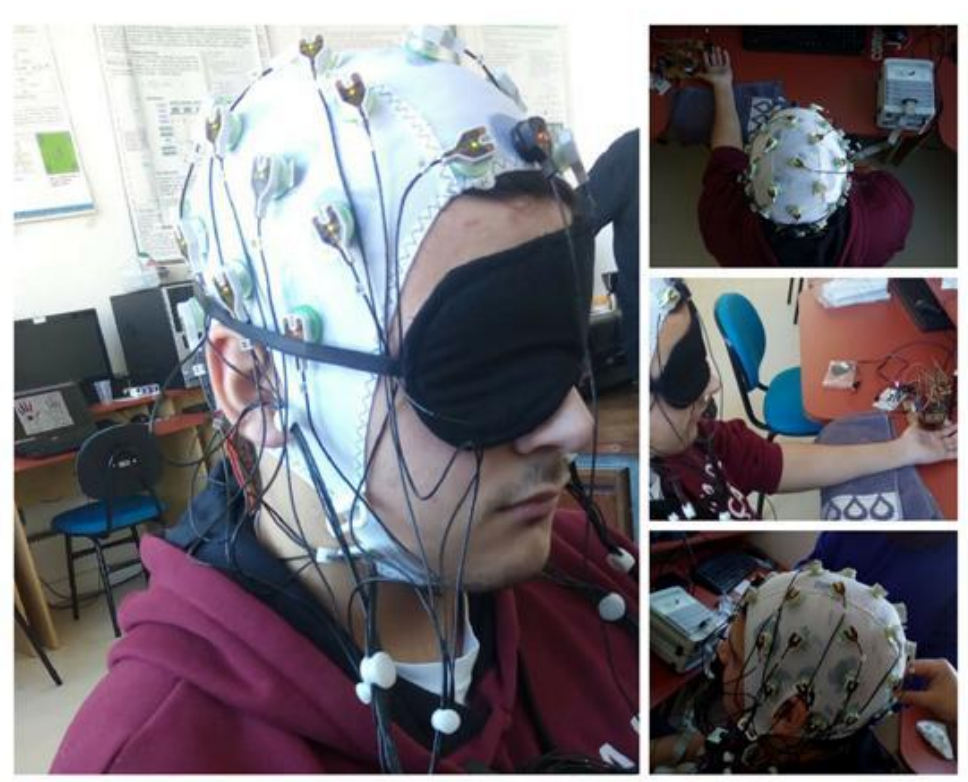

Figura 10: Sujeito durante a realização do teste. Fonte: os autores.

A região da visão na mão esquerda foi estimulada por cinco minutos, na Figura 11 pode-se notar a região estimulada assim como, a responsável pela visão no cérebro. A mão foi estimulada na parte de dentro e o lobo occipital está localizado em cima da nuca.

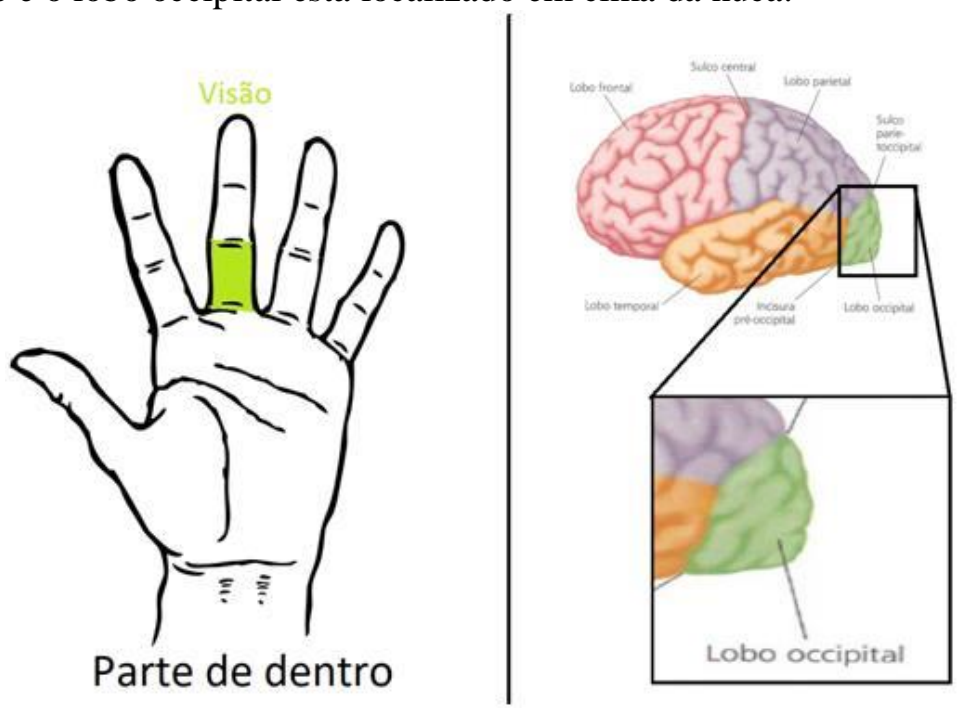

Figura 11: Região estimulada e responsável pela visão no cérebro. Fonte: os autores

\section{RESULTADOS}

Após realizar a coleta de sinais cerebrais utilizou-se o cenário da Figura 9 para visualizar os dados obtidos. Neste trabalho analisou-se o comportamento do lobo occipital ao estimular a região da mão referente aos olhos, devido ao fato de que esse lobo é o responsável pela visão, conforme Tabela 2. Para saber se a região está sendo analisada foi ativada conforme esperado segue-se a escala de cores da Figura 12. O nível amarelo refere-se a maior ativação da região enquanto a vermelha menor ativação.

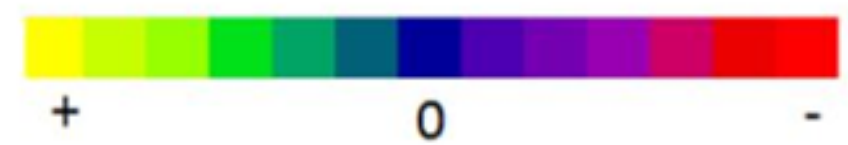

Figura 12: Escala de cores para representar as zonas de alta e baixa atividade. 
Analisou-se o comportamento da região e notou-se pela Figura 13 o nível de ativação em diferentes tempos durante a coleta. Nota-se que a região analisada possui baixo nível de ativação até 3 minutos conforme análise feita nos mapas 2D e 3D, A ao D. Aos quatro minutos de teste o lobo occipital começa a possuir alto nível de ativação conforme esperado, visto que esta região se refere a visão e a área estimulada aos olhos.

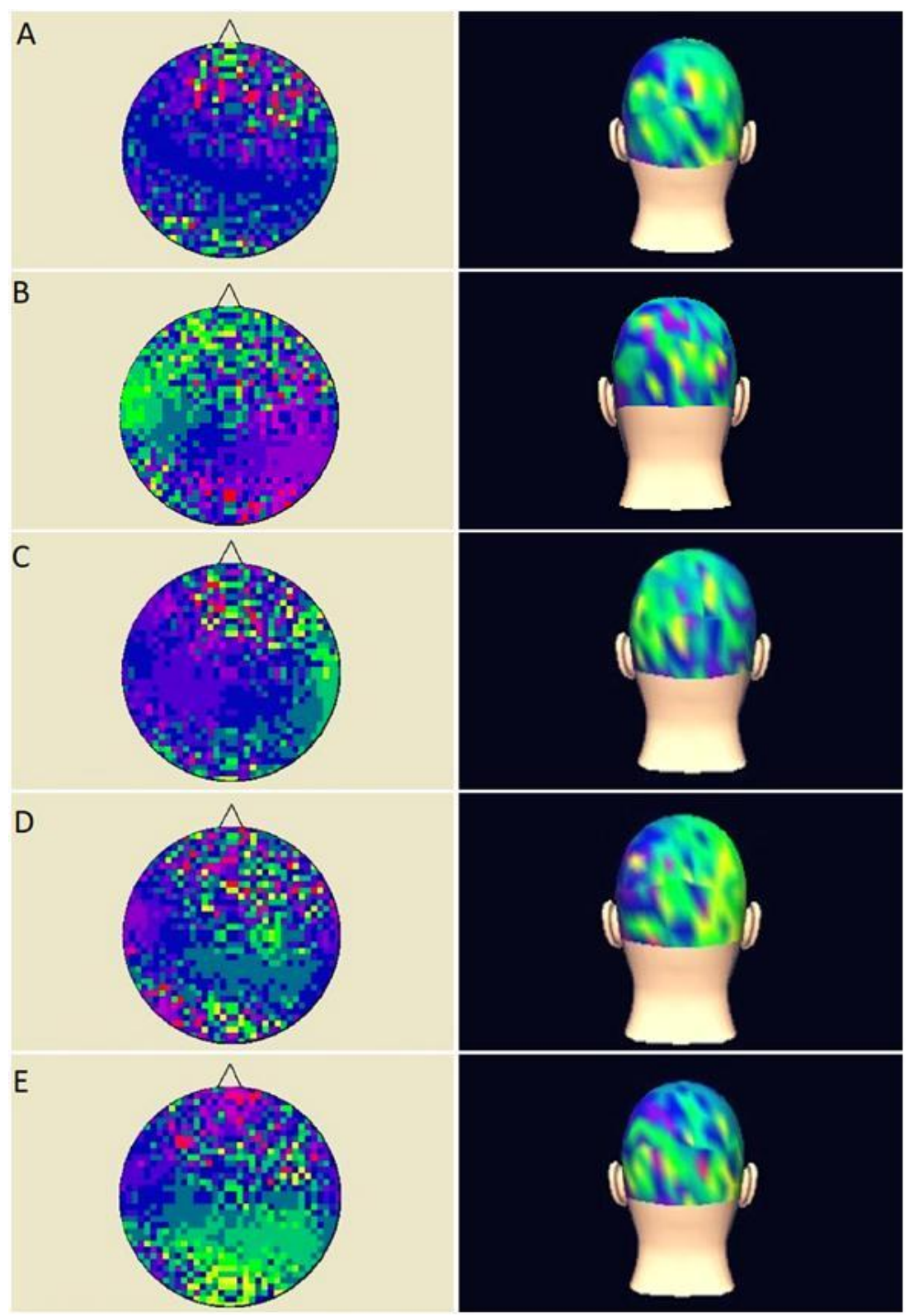

Figura 13: Principais regiões de ativação durante os primeiros segundos da coleta. A: 19 segundos B: 1 minuto C: 2 minutos D: 3 minutos E: 4 minutos. Fonte:os autores.

\section{CONCLUSÃO}

Este trabalho tem como objetivo analisar a relação entre as regiões cerebrais e a reflexologia, com base nos conceitos de neurociência. Como visto, a neurociência estuda o sistema nervoso com foco no cérebro de forma interdisciplinar. Com o auxílio de equipamentos e os estudos da desta área, é possível comprovar cientificamente problemas que ainda não foram validados pela comunidade científica. 
Este projeto encontra-se em desenvolvimento, entretanto com o primeiro teste realizado conclui-se a comprovação inicial da teoria da reflexologia. Ao ativar a região referente aos olhos ativa-se o lobo referente à visão, occipital, conforme apresentado.

As próximas etapas serão a aplicação do estímulo na região da visão em mais pessoas, em outras regiões da mão (parte de dentro e de fora) da mão esquerda, para ter um "grupo de controle", e realizar a análise das coletas de sinais cerebrais completa.

\section{AGRADECIMENTOS}

O projeto é desenvolvido pelo grupo de pesquisa do Laboratório de Modelagem e Simulação Social e Ambiental do Centro de Ciências Computacionais da Universidade Federal do Rio Grande.

\section{REFERÊNCIAS BIBLIOGRÁFICAS}

1. Jin Shin Jyutsu Inc. Autoaplicação: o início da jornada. Disponível em: http://www.jsjbrasil.com.br/autoaplicacao

2. Bear M, Connors B, Paradiso M. Neurociências: desvendando o sistema nervoso (4th ed.). Arthamed, 2017.

3. Mensia Technologies. Brain Products. ActiChamp: operating introductions. 2013. Disponível em: http://openvibe.inria.fr/

4. de Carvalho FAH. Reaprender a aprender: A pesquisa como alternativa metacognitiva. Tese de Doutorado. Pontifícia Universidade Católica do Rio Grande do Sul - Faculdade de Educação, 2007.

5. Gazzaniga M, Heatherton T. Ciência Psicológica, $4^{\mathrm{a}}$ edição, Artmed, 2012.

6. Hall N. Reflexologia: um método para melhorar a saúde. 12a edição, São Paulo: Pensamento, 2013.

7. Lent R. Cem bilhões de neurônios? Conceitos fundamentais de neurociência. $2^{\mathrm{a}}$ edição, Atheneu, 2002. 